\title{
Immune response to Leishmania antigens in an AIDS patient with mucocutaneous leishmaniasis as a manifestation of immune reconstitution inflammatory syndrome (IRIS): a case report
}

\author{
Luana Gois ${ }^{1}$, Roberto Badaró ${ }^{2}$, Robert Schooley ${ }^{3}$ and Maria Fernanda Rios Grassi ${ }^{1 *}$
}

\begin{abstract}
Background: After the onset of HAART, some HIV-infected individuals under treatment present a exacerbated inflammation in response to a latent or a previously treated opportunistic pathogen termed immune reconstitution inflammatory syndrome (IRIS). Few reports of tegumentary leishmaniasis have been described in association with IRIS. Moreover, the immunopathogenesis of IRIS in association with Leishmania is unclear.

Case presentation: The present study reports on a 29-year-old HIV-infected individual who developed mucocutaneous leishmaniasis associated with immune reconstitution inflammatory syndrome (IRIS) five months following highly active antiretroviral therapy (HAART). Severe lesions resulted in the partial destruction of the nasal septum, with improvement observed 15 days after treatment with Amphotericin B and corticosteroids. The immune response of this patient was evaluated before and after the lesions healed. IRIS was diagnosed in association with high levels of TNF-a and IL-6. Decreased production of IFN- $\gamma$ and a low IFN- $\gamma / \mathrm{LL}-10$ ratio were also observed in response to Leishmania antigens. After receiving anti-leishmanial treatment, the individual's specific Th1 immune response was restored.
\end{abstract}

Conclusion: The results suggest that the production of inflammatory cytokines by unstimulated T-lymphocytes could contribute to occurrence of leishmaniasis associated with IRIS.

Keywords: HIV, Leishmania, IRIS, Cytokines, Immune response

\section{Background}

Highly active antiretroviral therapy (HAART) has significantly benefited the majority of HIV-infected individuals. HAART results in a decrease in the plasma HIV-viral load and a partial recovery of CD4 + T-lymphocytes [1]. As a consequence, a sharp decrease is observed in morbidity and mortality rates [2]. However, some individuals under treatment experience clinical deterioration as a result of unregulated and rapid restoration of the immune response; i.e., the immune reconstitution inflammatory syndrome (IRIS). In these cases, an exacerbated inflammatory immune response against subclinical pathogens or residual antigens is observed [3].

\footnotetext{
* Correspondence: grassi@bahia.fiocruz.br

${ }^{1}$ Centro de Pesquisas Gonçalo Moniz, Fundação Oswaldo Cruz (FIOCRUZ), Salvador, Bahia, Brazil

Full list of author information is available at the end of the article
}

Most cases of IRIS are associated with the Mycobacterium avium complex, Mycobacterium tuberculosis, cytomegalovirus or herpes zoster [4,5]. Few cases of tegumentary leishmaniasis as a manifestation of IRIS in patients with AIDS have been reported to date [6-8]. Furthermore, the underlying immunological mechanisms of IRIS in association with this co-infection remain unclear. The present report describes a case of severe mucocutaneous leishmaniasis as a manifestation of IRIS in an HIV-infected patient from Brazil, and evaluates his cellular immune responses to Leishmania antigens.

\section{Materials and methods}

A case of mucocutaneous leishmaniasis in association with IRIS in an HIV-infected individual was recorded in 2009 at the Professor Edgar Santos University Hospital (HUPES), located in Salvador, Bahia-Brazil. The HUPES 
Institutional Research Review Board approved the present case report and informed written consent was obtained from the patient. Blood samples for immunological assessments were collected prior to and immediately after (the following day) the course of Amphotericin B and corticosteroid treatment. Peripheral blood mononuclear cells (PBMCs) were isolated by passage over a Ficoll-Hypaque gradient (Amersham Biosciences, Piscataway, NJ, USA). PBMCs were labeled with $1.5 \mu \mathrm{M}$ of carboxyfluorescein succinimidyl ester dye (CFSE, Molecular Probes, EugeneOR) and cultured for five days in the presence of either $10 \mu \mathrm{g} / \mathrm{mL}$ of soluble Leishmania antigen (SLA),[9] $5 \mu \mathrm{g} /$ $\mathrm{mL}$ of phytohaemagglutinin (PHA) or culture medium,. [10] Next, PBMCs were stained with $\mathrm{CD}^{+}$and $\mathrm{CD} 8^{+}$ monoclonal antibodies conjugated with phycoerythrin (PE) and allophycocyanin (APC). Cell acquisition was performed using a FACSAria Flow-Cytometer (Becton Dickinson, CA, USA) and subsequently analyzed by Flowjo $^{\mathrm{Tm}}$ software (v7.6, Tree Star, Inc. 1997-2009). The cell division index (DI) was used to quantify the proliferation intensity of $\mathrm{T}$-cell subsets $(\mathrm{DI}=0.06$ for $\mathrm{CD} 4+$ and 0.09 for CD8+ T-cells.) The frequencies of $\mathrm{CD}_{4}^{+}$and $\mathrm{CD}^{+} \mathrm{T}$-cells producing intracellular cytokines were quantified using flow cytometry. PBMCs were cultured in the presence of SLA, PHA or culture medium for $18 \mathrm{~h}$. Heatinactivated human $\mathrm{AB}$ serum, brefeldin $\mathrm{A}$ and monensin were added to all cultures in the final four hours. Next, PBMCs were stained with anti-CD4-fluorescein isothiocyanate (FITC) and anti-CD8-APC, then permeabilized with PBS-BSA-Saponin $0.2 \%$ and incubated with anti-
INF- $\gamma$-PE, anti-TNF- $\alpha-P E$, and anti-IL-10-PE (Becton Dickinson, CA, USA). Plasma cytokine levels were quantified using the BD Cytometric Bead Array (CBA) Human Th1/Th2 Cytokine Kit II (San Jose, CA, USA).

\section{Case presentation}

The patient, a 29-year-old HIV-1-infected male, reported being treated for pulmonary tuberculosis in 2006. In 2007, the patient's serology for HIV tested positive. Eight months later, the patient reported an ulcerative lesion in his lower right limb, which was diagnosed as tegumentary leishmaniasis. He subsequently received pentavalent antimony therapy, resulting in the healing of this lesion. In December 2008, the patient began HAART therapy (zidovudine, lamivudine, and efavirenz). At this time, his $\mathrm{CD} 4^{+}$T-cell count was 160 cells $/ \mathrm{mm}^{3}$ and viral load was 92,479 copies/mL. In May 2009, he presented with ulcerative lesions on his face in association with nasal obstruction. At this point, his $\mathrm{CD} 4^{+} \mathrm{T}$-cell count was 516 cells $/ \mathrm{mm}^{3}$ with an undetectable HIV viral load. The lesions subsequently progressed, resulting in severe inflammation characterized by a pronounced swelling of the lips, nasal and mentum regions. He was admitted to Hospital Professor Edgard Santos (HUPES) in August 2009 (Figure 1). The lesions were crusty in appearance and a partial destruction of the patient's upper lip and nose was observed (Figure 2A and B). In addition, myiasis was observed in his necrotic lesions. Destruction of the nasal septum was confirmed by computerized tomography of the paranasal sinus cavities (Figure 2C).

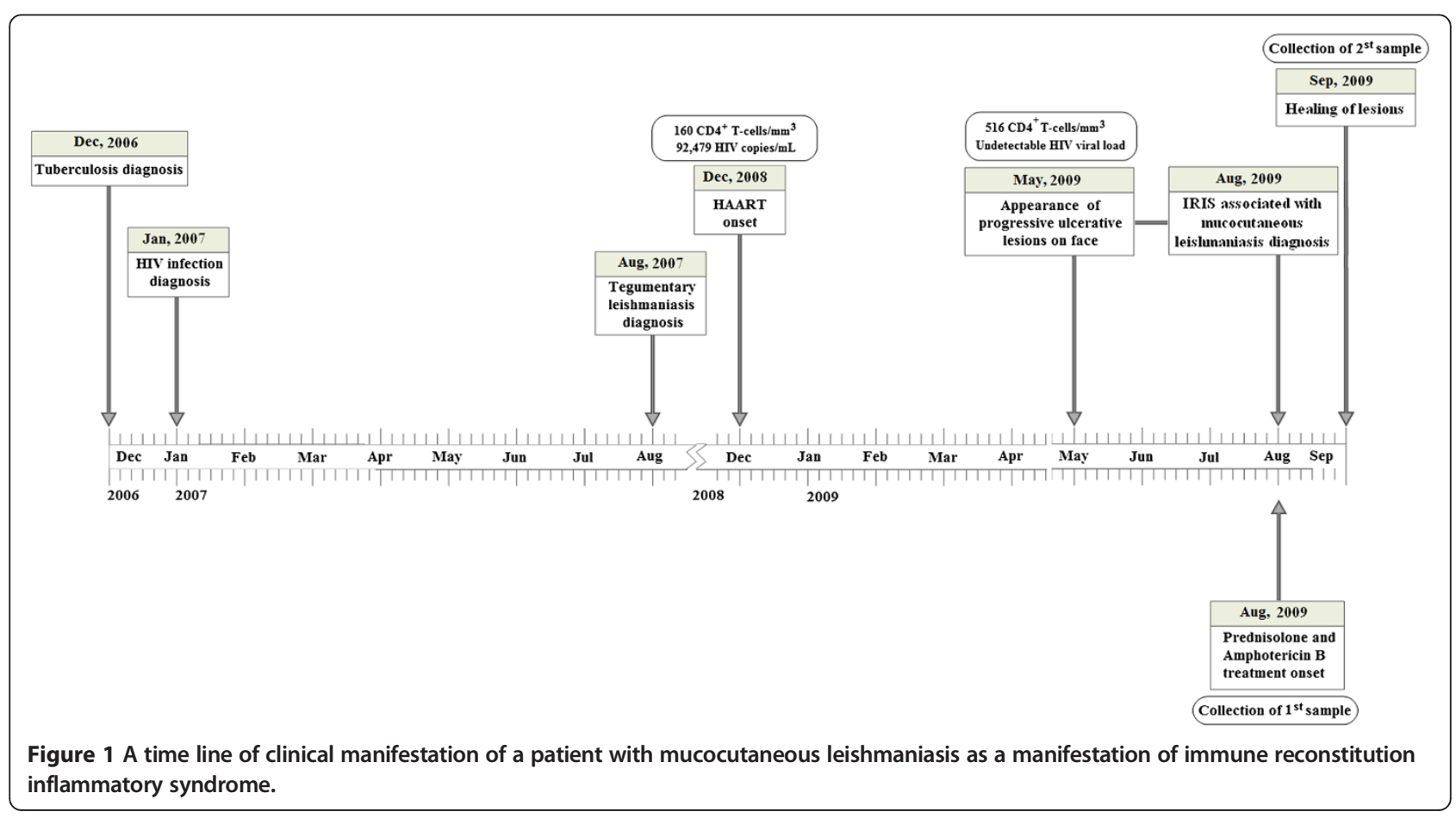




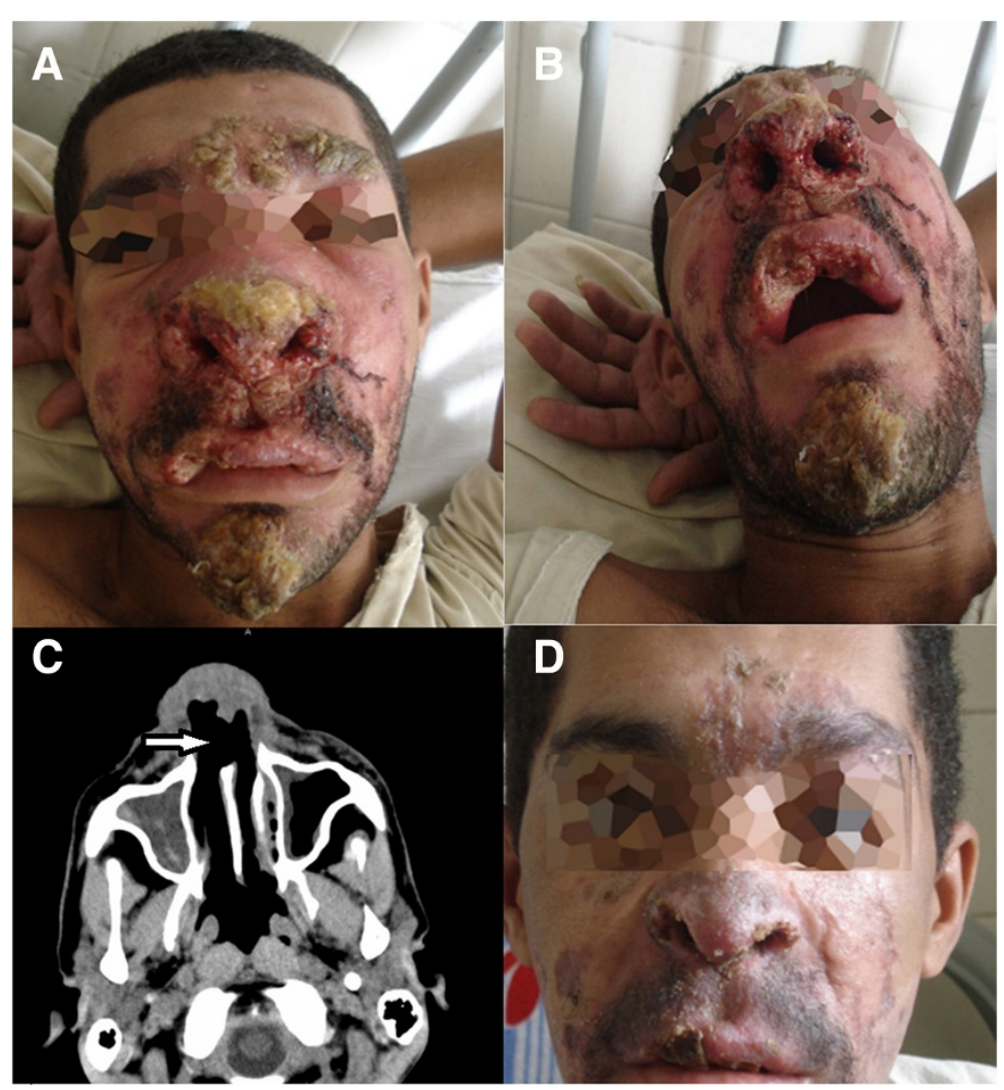

Figure 2 An HIV-infected patient with mucocutaneous leishmaniasis as a manifestation of immune reconstitution inflammatory syndrome (IRIS). In May 2009, five months after the initiation of HAART therapy, he presented with ulcerative lesions on his face in association with nasal obstruction. A and B: By August 2009, the lesions progressed and severe inflammation with pronounced swelling of the lips, nasal and mentum regions are pictured. C: Computerized tomography of the paranasal sinus cavities shows partial destruction of the nasal septum (white arrow) (August, 2009). D: Healing of lesions observed following treatment with Prednisolone and Amphotericin B (September 2009).

A skin biopsy revealed the presence of granulomatous lesions. Caseous necrosis was identified by a cervical lymph node biopsy. Amastigote forms of Leishmania spp. were found in both skin and lymph node biopsies. The skin test for Leishmania was positive $(15 \mathrm{~mm})$ and indirect ELISA for soluble L. brasiliensis antigens was positive, while ELISA for rK39 was negative. IgG anti-L. braziliensis levels were measured using indirect ELISA for soluble L. braziliensis antigens. The specie determination was further confirmed using a serial realtime quantitative PCR assay system, as described by Weirather, JL, 2011 [11].

The patient was then diagnosed with mucocutaneous leishmaniasis as a manifestation of IRIS and HAART was discontinued. He was subsequently treated with $80 \mathrm{mg} /$ day of Prednisolone and $1 \mathrm{mg} / \mathrm{Kg} /$ day of Amphotericin B from August to September 2009. After 15 days of treatment, improvement in the mucocutaneous lesions and in the patient's cervical lymphadenopathy was observed (Figure 2D). After two months of hospitalization, the lesions had completely healed and the patient was discharged. HAART therapy was subsequently reintroduced.
Immune response to Leishmania antigens during and after IRIS

Prior to treatment with Amphotericin B, the patient's proliferative response to SLA was undetectable in both $\mathrm{CD}^{+}$and $\mathrm{CD}^{+}{ }^{+}$T-cell subsets (Figure 3 - white bars). In the absence of SLA stimulus, the production of cytokines (IFN- $\gamma$, TNF- $\alpha$ and IL-10) by both $\mathrm{CD} 4^{+}$and $\mathrm{CD} 8^{+}$ T-cells were similar under both conditions. In addition, IL-10 production was undetectable following SLA stimulation in the $\mathrm{CD}^{+} \mathrm{T}$-cell subset (Figure 4A). Following leishmanial treatment, a proliferative response to SLA was observed in both $\mathrm{CD}^{+}$(DI: 0.3 ) and $\mathrm{CD} 8^{+} \mathrm{T}$-cell subsets (DI: 0.2) (Figure 3 - black bars). In the absence of SLA stimulus, IFN- $\gamma$, TNF- $\alpha$ and IL-10 production by $\mathrm{CD} 4^{+}$T-cells was undetectable, and few $\mathrm{CD}^{+}$T-cells were observed producing these cytokines. By contrast, in response to SLA stimulation, a high proportion of $\mathrm{CD} 4^{+}$ and $\mathrm{CD} 8^{+}$T-cells producing TNF- $\alpha$ and IL-10 was detected (Figure 4B). Production of IFN- $\gamma$ was markedly higher in $\mathrm{CD}^{+}$cells in comparison with that of $\mathrm{CD}_{4}^{+}$ T-cells. Plasmatic levels of INF- $\gamma$, TNF- $\alpha$, IL- 2 and IL-10 were higher at the conclusion of treatment with 


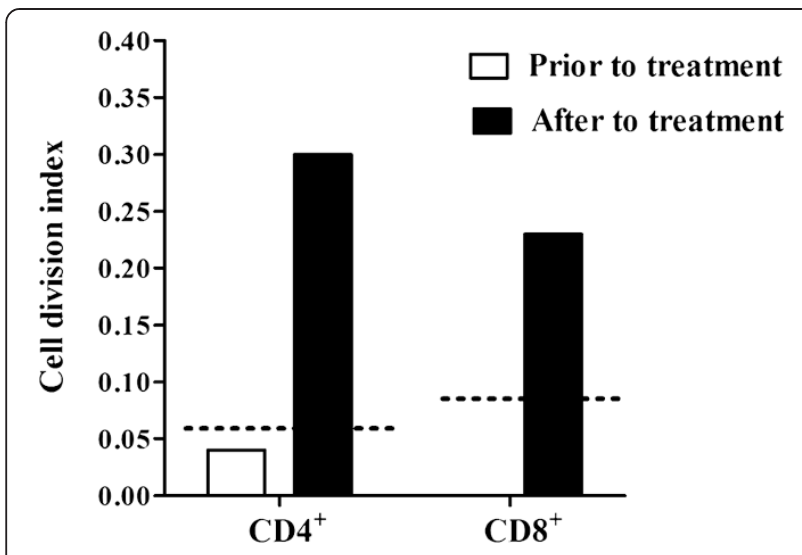

Figure 3 Evaluation of CD4+ and CD8+ T-lymphocyte proliferation in response to soluble Leishmania antigens (SLA) in a patient with mucocutaneous leishmaniasis as manifestation of IRIS. Blood samples were collected before (August 2009) and one day following the conclusion of Amphotericin B and corticosteroid treatment (September 2009). The cell division index was calculated using Flowjo ${ }^{\mathrm{TM}}$ software. White and black bars represent the T-cell proliferative responses to Leishmania antigens prior to and after Amphotericin B treatment, respectively. Dashes represent the threshold value with respect to a positive proliferative response (above 0.06 for CD4+ T-cell and above 0.09 CD8+ T-cell subset).
Amphotericin B, while IL- 6 decreased, and the IFN- $\gamma /$ IL-10 ratio rose from 0.0 to 3.6 over the course of treatment (Table 1).

\section{Discussion}

Cutaneous leishmaniasis as a manifestation of IRIS may appearance, following the introduction of HAART and consequent restoration of immunity, as a new disease or as the progression of latent disease [12]. In the present report, the patient's lesions developed five months after the initiation of antiretroviral therapy, concurrent with the recovery of the number of $\mathrm{CD} 4^{+} \mathrm{T}$-cells.

To the best of our knowledge, only two other cases of patients infected with HIV and the clinical form of mucocutaneous leishmaniasis as a manifestation of IRIS have been described to date [6]. In both of these cases, disseminated skin lesions (on the arms, lower limbs and feet) and lesions in the nasal, oropharyngeal, as well as genital mucosa were reported. Although genital lesions have been reported in one-third of HIV/Leishmania coinfected patients $[12,13]$, the patient described herein did not show genital involvement or widespread skin lesions. His lesions were restricted to the facial area, especially in the nasal and oropharyngeal mucosa, with intense inflammation resulting in destruction of the nasal septum.
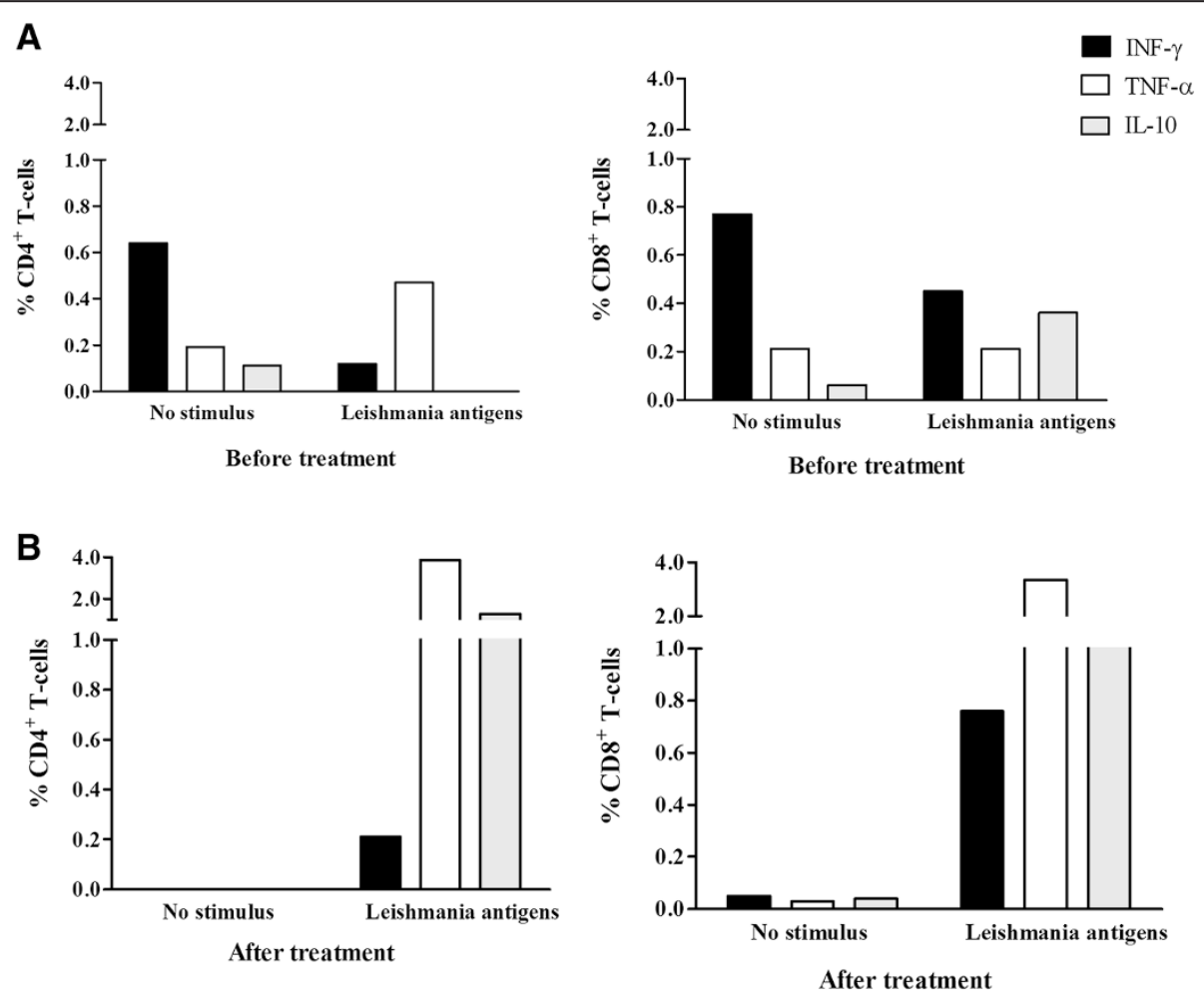

Figure 4 Proportion of CD4+ and CD8+ T-cells producing intracellular IFN- $\gamma$, TNF- $a$ and IL-10 after culturing without stimulus, and in the presence of SLA. Blood samples were collected in August 2009 from a patient with mucocutaneous leishmaniasis as manifestation of IRIS before (A) and one day after the end (B) of Amphotericin B and corticosteroid treatment (September 2009). 
Table 1 Cytokine levels in the plasma of a patient with mucocutaneous leishmaniasis as manifestation of IRIS, before and after Amphotericin B treatment

\begin{tabular}{lll}
\hline Cytokine & \multicolumn{2}{l}{ Amphotericin B treatment } \\
\cline { 2 - 3 } & Before & After \\
\hline IFN- $\gamma$ & 0.0 & 47.7 \\
TNF- $\alpha$ & 11.1 & 17.8 \\
IL-10 & 5.3 & 13.3 \\
IL-2 & 15.0 & 22.5 \\
IL-4 & 7.1 & 8.2 \\
IL-6 & 17.6 & 10.6 \\
IFN- $\gamma /$ /L-10 ratio & 0.0 & 3.6 \\
\hline Data
\end{tabular}

Data are presented in $\mathrm{pg} / \mathrm{mL}$. Cytokine levels were quantified before and one day after the end of Amphotericin B and corticosteroid treatment.

Our results suggest that the mucosal damage resulting from mucocutaneous leishmaniasis as a manifestation of IRIS in this patient was correlated with an unspecific inflammatory milieu. During the course of IRIS, CD4 $4^{+}$ and $\mathrm{CD}^{+}$T-lymphocytes produced very low levels of IFN- $\gamma$ and TNF- $\alpha$ in response to Leishmania antigens, yet high levels of IFN- $\gamma$ by both $\mathrm{CD}^{+}$and $\mathrm{CD}^{+}{ }^{+} \mathrm{T}$-cells were observed in the absence of antigen stimulation. Conversely, after the lesions healed, a specific immune response to Leishmania antigens was reestablished and a profound reduction in the spontaneous production of cytokines was observed. The decreased T-cell proliferation and low antigen-induced cytokine responses observed in this patient during the course of IRIS could be more suggestive of immunosuppression to Leishmania antigens than a hyper-responsive state. However, the fact that the lesions appeared at the same time the patient's immune system demonstrated recovery (the $\mathrm{CD} 4^{+} \mathrm{T}$ lymphocyte count was higher than 500 cells $/ \mathrm{mm}^{3}$ and HIV viral load was undetectable) is supportive of an IRIS diagnosis. Moreover, the initial clinical presentation of mucosal leishmaniasis, which appeared five months after HAART initiation, progressed to an intense inflammatory response with partial destruction of the nasal septum in less than four months.

During IRIS, the patient had a positive skin test for Leishmania, while his antigen-specific T-cell proliferation was undetectable. This discrepancy could be explained by the dynamic of immune restoration following HAART. The restoration of antigen-specific $\mathrm{CD} 4^{+} \mathrm{T}$-cell responses in vitro is mostly correlated with $\mathrm{CD} 4^{+}$memory T-cell reconstitution; whereas the improvement of delayed type hypersensitivity is associated with the suppression of viraemia [14]. However, it was not possible to quantify antigen-specific central and effector memory $\mathrm{CD} 4^{+}$T-lymphocytes for this patient, during IRIS or after healing of lesions. In addition, an impairment of in vitro proliferative response to Leishmania antigens could be linked to the activation and exhaustion of immune system found during IRIS [15]. Yet, intrinsic differences among tests for measuring cellular immune function could explain these divergent results.

In the present case, the participation of a specific response to Leishmania antigens with respect to the development of skin and mucosal lesions cannot be excluded, since a Leishmania-specific response was not evaluated in situ. A specific recruitment of $\mathrm{CD}_{4}^{+}$and $\mathrm{CD} 8^{+} \mathrm{T}$-cells to the ulcerative lesion is described in patients with both cutaneous and mucosal leishmaniasis [16,17]. Specifically, in the mucosal lesions it is observed high number of IFN- $\gamma$-producing cells [16]. Indeed, a decreased type1 immune response to Leishmania antigens in peripheral blood is associated with intense recruitment of Leishmania-specific T-cells to the lesions, which is classically found in HIV-uninfected patients with disseminated leishmaniasis, yet cytokine production in tegumentary lesions was observed to be similar to that found in patients with mucocutaneous and cutaneous leishmaniasis [18]. Following healing, though $\mathrm{CD} 4^{+}$and $\mathrm{CD} 8^{+} \mathrm{T}$-cells persist in treated lesions, the number of circulating antigen-specific $\mathrm{CD} 4^{+}$and $\mathrm{CD} 8^{+} \mathrm{T}$-cells increases in peripheral blood $[19,20]$. Thus, in this patient the absence of proliferative response to Leishmania antigens during IRIS might be due to sequestration of T-cells inside lesions. After healing, these cells were redistributed to peripheral blood.

The elevated cytokine production observed in nonstimulated cells may be a consequence of activated memory $\mathrm{CD} 4^{+} \mathrm{T}$-cells specific for pathogens other than Leishmania. These cells recirculate from lymphoid organs into the peripheral blood stream during the first two months of HAART $[1,21]$. Moreover, the chronic activation of the immune system by HIV itself may also contribute to the inflammatory state observed during the course of IRIS [22].

High levels of IL- 6 and TNF- $\alpha$ have been previously described in patients with other infectious diseases in association with IRIS [23-25]. Additionally, elevated proinflammatory cytokine production is considered to be a predictor of IRIS development in HIV-infected patients at the onset of HAART [26]. Considering the plasma levels of TNF- $\alpha$ in two HIV-uninfected patients with active mucocutaneous leishmaniasis evaluated at our laboratory $(22 \mathrm{pg} / \mathrm{mL}$ and $13 \mathrm{pg} / \mathrm{mL})$ [27], the levels observed in this patient during IRIS were similar. Following treatment with Amphotericin B and corticosteroids, an increase in plasmatic IFN- $\gamma$, as well as in the IFN- $\gamma /$ IL-10 ratio, was observed in the present case, while TNF- $\alpha$ remained stable. Although treatment with corticosteroids usually decreases the production of inflammatory cytokines [28], a decrease in the spontaneous production of IFN- $\gamma$ and TNF- $\alpha$ was observed in 
this patient only in vitro, but not in his plasma. This finding may be due to the fact that post-treatment cytokine quantification was performed in the plasma by a single measurement just one day following the conclusion of treatment. It is possible that subsequent measurements would have found decreases in TNF- $\alpha$ in the plasma.

Furthermore, the nonspecific activation of the immune system could be a consequence of an impaired regulatory T-cell response or a decrease in the proportion of these cells, since IL-10 produced by Leishmania-specific $\mathrm{CD} 4{ }^{+} \mathrm{T}$-lymphocytes was not detected during the course of IRIS [8]. The proportion of regulatory T-cells (1.8\%) in our patient prior to treatment was found to be low (data not shown). An imbalance between the effector and regulatory responses may also play a role in the pathogenesis of IRIS $[29,30]$.

IRIS is characterized by an intense inflammatory reaction, leading to tissue destruction concurrent with an increase in the number of $\mathrm{CD}_{4}^{+}$T-cells following HAART. No convincing evidence has been presented in regard to whether $\mathrm{CD} 4^{+} \mathrm{T}$-cells specific to opportunistic pathogens are deregulated during IRIS, much less if these cells are involved in the pathogenesis of IRIS. Moreover, the literature contains no reports that directly link CD4 ${ }^{+}$T-cells specific to Leishmania antigens with clinical manifestations of leishmaniasis in association with IRIS. However, several reports have shown a recovery of $\mathrm{CD}_{4}^{+}$T-cells specific to Mycobacterium tuberculosis, Mycobacterium avium complex and Cryptococcal neoformans in patients who developed IRIS in association with these infections [18,29,31]. Interestingly, another study found no clear association between the recovery of $M$. tuberculosis-specific $\mathrm{CD} 4^{+} \mathrm{T}$-cells and tuberculosis in association with IRIS [29].

It has been suggested that the absence of T-cells, such as occurs in the course of AIDS, may lead to the growth of intracellular pathogens inside macrophages that never become fully activated, and thus exert no effector function. When antigen-specific $\mathrm{CD} 4^{+} \mathrm{T}$-cells are restored following HAART, these cells may intensely stimulate macrophages and possibly other innate immune cells that produce large amounts of proinflammatory cytokines, resulting in inflammation and tissue destruction [31].

\section{Conclusion}

In summary, the results presented herein suggest that Leishmania-associated IRIS occurred concurrently with the production of proinflammatory cytokines by unstimulated T-lymphocytes, which is supported by the absence of a specific host immune response against Leishmania antigens in the peripheral blood of this patient.

\section{Consent}

Written informed consent was obtained from the patient for publication of this case report and any accompanying images. A copy of the written consent is available for review by the Editor of this journal.

\section{Competing interests}

The authors declare that they have no competing interests.

\section{Authors' contributions}

LG carried out the immunoassays, performed the statistical analysis and prepared of manuscript. RB participated in the design of the study, carried out the case report and helped to draft the manuscript. RS participated in the design of the STUDY and of the revised the manuscript. MFRG conceived of the study, and participated in its design and coordination and helped to draft the manuscript. All authors read and approved the final manuscript.

\section{Acknowledgment}

Soluble Leishmania antigen (SLA) was kindly provided by Dr. Geraldo Gileno at the LPBI-(Laboratório de Patologia e Biointervenção) Fiocruz Bahia-Brazil. We would like thank Andris K. Walter for his assistance in English revision.

\section{Financial support}

This study was supported by the UCSD Center for AIDS Research, NIH grant P30Al036214.

\section{Author details}

${ }^{1}$ Centro de Pesquisas Gonçalo Moniz, Fundação Oswaldo Cruz (FIOCRUZ), Salvador, Bahia, Brazil. ${ }^{2}$ Hospital Professor Edgard Santos, Universidade Federal da Bahia, Salvador, Bahia, Brazil. ${ }^{3}$ Department of Medicine, University of California, San Diego, USA.

Received: 18 September 2014 Accepted: 20 January 2015 Published online: 03 February 2015

\section{References}

1. Autran B, Carcelain G, Li TS, Blanc C, Mathez D, Tubiana R, et al. Positive effects of combined antiretroviral therapy on CD4+ T cell homeostasis and function in advanced HIV disease. Science. 1997;277(5322):112-6.

2. Palella Jr FJ, Delaney KM, Moorman AC, Loveless MO, Fuhrer J, Satten GA, et al. Declining morbidity and mortality among patients with advanced human immunodeficiency virus infection. HIV Outpatient Study Investigators. N Engl J Med. 1998;338(13):853-60.

3. Murdoch DM, Venter WD, Van Rie A, Feldman C. Immune reconstitution inflammatory syndrome (IRIS): review of common infectious manifestations and treatment options. AIDS Res Ther. 2007;4:9.

4. Shelburne 3rd SA, Hamill RJ, Rodriguez-Barradas MC, Greenberg SB, Atmar RL, Musher DW, et al. Immune reconstitution inflammatory syndrome: emergence of a unique syndrome during highly active antiretroviral therapy. Medicine (Baltimore). 2002;81(3):213-27.

5. French MA. HIV/AIDS: immune reconstitution inflammatory syndrome: a reappraisal. Clin Infect Dis. 2009;48(1):101-7.

6. Posada-Vergara MP, Lindoso JA, Tolezano JE, Pereira-Chioccola VL, Silva MV, Goto H. Tegumentary leishmaniasis as a manifestation of immune reconstitution inflammatory syndrome in 2 patients with AIDS. J Infect Dis. 2005;192(10):1819-22.

7. Sinha S, Fernandez G, Kapila R, Lambert WC, Schwartz RA. Diffuse cutaneous leishmaniasis associated with the immune reconstitution inflammatory syndrome. Int J Dermatol. 2008;47(12):1263-70.

8. Chrusciak-Talhari A, Ribeiro-Rodrigues R, Talhari C, Silva Jr RM, Ferreira LC, Botileiro SF, et al. Tegumentary leishmaniasis as the cause of immune reconstitution inflammatory syndrome in a patient co-infected with human immunodeficiency virus and Leishmania guyanensis. Am J Trop Med Hyg. 2009;81(4):559-64.

9. Carvalho EM, Johnson WD, Barreto E, Marsden PD, Costa JL, Reed S, et al. Cell mediated immunity in American cutaneous and mucosal leishmaniasis. J Immunol. 1985;135(6):4144-8.

10. Lyons AB, Doherty KV: Flow cytometric analysis of cell division by dye dilution. Curr Protoc Cytom 2004, Chapter 9:Unit 911. 
11. Weirather $J$, Jeronimo SM, Gautam S, Sundar S, Kang M, Kurtz MA, et al. Serial quantitative PCR assay for detection, species discrimination, and quantification of Leishmania spp. in human samples. J Clin Microbiol. 2011:49(11):3892-904.

12. Goto H, Lindoso JA. Current diagnosis and treatment of cutaneous and mucocutaneous leishmaniasis. Expert Rev Anti Infect Ther. 2010;8(4):419-33.

13. Lindoso JA, Barbosa RN, Posada-Vergara MP, Duarte MI, Oyafuso LK, Amato VS, et al. Unusual manifestations of tegumentary leishmaniasis in AIDS patients from the New World. Br J Dermatol. 2009;160(2):311-8.

14. Wendland T, Furrer H, Vernazza PL, Frutig K, Christen A, Matter L, et al. HAART in HIV-infected patients: restoration of antigen-specific CD4 T-cell responses in vitro is correlated with CD4 memory T-cell reconstitution, whereas improvement in delayed type hypersensitivity is related to a decrease in viraemia. AIDS. 1999;13(14):1857-62.

15. Nakanjako D, Ssewanyana I, Mayanja-Kizza H, Kiragga A, Colebunders R, Manabe YC, et al. High T-cell immune activation and immune exhaustion among individuals with suboptimal CD4 recovery after 4 years of antiretroviral therapy in an African cohort. BMC Infect Dis. 2011;11:43.

16. Faria DR, Gollob K, Barbosa Jr J, Schriefer A, Machado PR, Lessa H, et al. Decreased in situ expression of interleukin-10 receptor is correlated with the exacerbated inflammatory and cytotoxic responses observed in mucosal leishmaniasis. Infect Immun. 2005;73(12):7853-9.

17. Santos Cda S, Boaventura V, Ribeiro Cardoso C, Tavares N, Lordelo MJ, Noronha A, et al. CD8(+) granzyme B(+)-mediated tissue injury vs. CD4(+) IFNgamma(+)-mediated parasite killing in human cutaneous leishmaniasis. J Invest Dermatol. 2013;133(6):1533-40.

18. Machado PR, Rosa ME, Costa D, Mignac M, Silva JS, Schriefer A, et al. Reappraisal of the immunopathogenesis of disseminated leishmaniasis: in situ and systemic immune response. Trans R Soc Trop Med Hyg. 2011;105(8):438-44.

19. Amato VS, de Andrade HF, Duarte MI. Mucosal leishmaniasis: in situ characterization of the host inflammatory response, before and after treatment. Acta Trop. 2003;85(1):39-49.

20. Brelaz-de-Castro MC, de Almeida AF, de Oliveira AP, de Assis-Souza M, da Rocha LF, Pereira VR. Cellular immune response evaluation of cutaneous leishmaniasis patients cells stimulated with Leishmania (Viannia) braziliensis antigenic fractions before and after clinical cure. Cell Immunol. 2012;279(2):180-6.

21. Kelleher AD, Carr A, Zaunders J, Cooper DA. Alterations in the immune response of human immunodeficiency virus (HIV)-infected subjects treated with an HIV-specific protease inhibitor, ritonavir. J Infect Dis. 1996;173(2):321-9.

22. Pantaleo G, Graziosi C, Fauci AS. New concepts in the immunopathogenesis of human immunodeficiency virus infection. N Engl J Med. 1993;328(5):327-35.

23. Stone SF, Price P, Keane NM, Murray RJ, French MA. Levels of IL-6 and soluble IL-6 receptor are increased in HIV patients with a history of immune restoration disease after HAART. HIV Med. 2002;3(1):21-7.

24. Antonelli LR, Mahnke $Y$, Hodge JN, Porter BO, Barber DL, DerSimonian R, et al. Elevated frequencies of highly activated CD4+ T cells in HIV+ patients developing immune reconstitution inflammatory syndrome. Blood. 2010;116 (19):3818-27.

25. Morlese JF, Orkin CM, Abbas R, Burton C, Qazi NA, Nelson MR, et al. Plasma IL-6 as a marker of mycobacterial immune restoration disease in HIV-1 infection. AIDS. 2003;17(9):1411-3.

26. Grant PM, Komarow L, Lederman MM, Pahwa S, Zolopa AR, Andersen J, et al. Elevated interleukin 8 and T-helper 1 and T-helper 17 cytokine levels prior to antiretroviral therapy in participants who developed immune reconstitution inflammatory syndrome during ACTG A5164. J Infect Dis. 2012;206(11):1715-23.

27. Rodrigues MZ, Grassi MF, Mehta S, Zhang XQ, Gois LL, Schooley RT, et al. Th1/Th2 Cytokine Profile in Patients Coinfected with HIV and Leishmania in Brazil. Clin Vaccine Immunol. 2011;18(10):1765-9.

28. Meintjes G, Skolimowska KH, Wilkinson KA, Matthews K, Tadokera R, Conesa-Botella A, et al. Corticosteroid-modulated immune activation in the tuberculosis immune reconstitution inflammatory syndrome. Am J Respir Crit Care Med. 2012;186(4):369-77.

29. Meintjes G, Wilkinson KA, Rangaka MX, Skolimowska K, van Veen K, Abrahams M, et al. Type 1 helper T cells and FoxP3-positive T cells in HIV-tuberculosis-associated immune reconstitution inflammatory syndrome. Am J Respir Crit Care Med. 2008;178(10):1083-9.
30. Lim A, D'Orsogna L, Price $P$, French MA. Imbalanced effector and regulatory cytokine responses may underlie mycobacterial immune restoration disease. AIDS Res Ther. 2008;5:9.

31. Barber DL, Andrade BB, Sereti I, Sher A. Immune reconstitution inflammatory syndrome: the trouble with immunity when you had none. Nat Rev Microbiol. 2012;10(2):150-6.

\section{Submit your next manuscript to BioMed Central and take full advantage of:}

- Convenient online submission

- Thorough peer review

- No space constraints or color figure charges

- Immediate publication on acceptance

- Inclusion in PubMed, CAS, Scopus and Google Scholar

- Research which is freely available for redistribution 